Article

\title{
Invisible and Insecure in Rural America: Cultivating Dignity in Local Food Security Initiatives
}

\author{
Amy Herrington ${ }^{1}$ and Tamara L. Mix ${ }^{2, *(D)}$ \\ 1 Vermont Law School, South Royalton, VT 05068, USA; herringtonamy@gmail.com \\ 2 Department of Sociology, Oklahoma State University, Stillwater, OK 74078, USA \\ * Correspondence: tamara.mix@okstate.edu; Tel.: +1-405-744-6104
}

Citation: Herrington, A.; Mix, T.L. Invisible and Insecure in Rural

America: Cultivating Dignity in Local Food Security Initiatives.

Sustainability 2021, 13, 3109. https://

doi.org/10.3390/su13063109

Academic Editor:

Francesco Caracciolo

Received: 29 January 2021

Accepted: 10 March 2021

Published: 12 March 2021

Publisher's Note: MDPI stays neutral with regard to jurisdictional claims in published maps and institutional affiliations.

Copyright: (c) 2021 by the authors. Licensee MDPI, Basel, Switzerland. This article is an open access article distributed under the terms and conditions of the Creative Commons Attribution (CC BY) license (https:/ / creativecommons.org/licenses/by/ $4.0 /)$.

\begin{abstract}
The United States' neoliberal approach to governance promotes structural inequalities that shape individuals' sense of dignity. We employ qualitative in-depth interviews and ethnographic field study to examine dignity construction via daily experiences with food access and foodways. Situating our study within a rural Oklahoma community with high food insecurity rates, we ask: How does structural inequality impact individuals' daily experiences with dignity construction? How is a sense of dignity influenced by daily experiences with food access and foodways within the context of community-based food initiatives? We address structural inequality and the resulting social hierarchy of food security, focusing on three overlapping social arenas-relational, individual, and institutional. Relational interactions in food access spaces promote dignity when interactions are characterized by symmetrical social encounters. Dignity in the individual arena centers on foodways, cultural or familial traditions, and role-taking as a food provider. In the institutional arena, dignity is influenced by structures and operational approaches. Our research contributes to literatures informing policies and strategies employed by community-led, rights-based food aid systems in advanced capitalist nations. Efforts prioritize and promote human dignity, despite neoliberal, advanced capitalist governments' failure to address structural inequalities as a root cause of food insecurity.
\end{abstract}

Keywords: food insecurity; structural inequality; food access; foodways; neoliberal; advanced capitalist nations; right to food; human rights and dignity; community-based food initiatives; social hierarchy of food

\section{Introduction}

Despite longstanding recognition of food and nutrition as critical to health, only in recent years have scholars and public health experts begun to widely acknowledge food's role in exacerbating health inequalities in wealthy, advanced, capitalist nations [1,2]. Food insecurity is defined as "the inability to consume an adequate quality or sufficient quantity of food in socially acceptable ways, or the uncertainty that one will be able to do so" [3] (p. 120). Access to adequate, culturally appropriate, healthy foods is unequally distributed amongst social groups in the United States due to factors such as residential segregation, poverty, and neighborhood deprivation [4,5]. Perpetuated by growing levels of economic inequality, food insecurity is linked to low wages, rising healthcare and housing costs, inflation, and higher food expense [6]. Although the United States Department of Agriculture (USDA) reports in 2020 that "the prevalence of [overall] food insecurity declined, for the first time, to the pre-recession (2007) level of 11.1 percent," higher rates of food insecurity persist for people of color, low-income individuals, households with single mothers, individuals without college degrees, and adults with disabilities [7].

Disparities in nutrient intake and food patterns among various groups suggests that structural inequalities in advanced capitalist nations are core impediments to achieving food security for all individuals. Despite calls to focus on structural inequalities in food 
and nutrition policy interventions [2], policy-makers in advanced capitalist nations question whether low-income, food insecure individuals have the competency or capacity to manage food budgets, choose nutritional foods, or prepare adequate meals [1]. Social movements to reform the food system, such as the food justice movement, challenge neoliberal philosophies of the United States and other advanced capitalist nations and advocate for a rights-based approach, underscoring the right to food security as a primary function of a democratic and just society [1,8-10]. Implementing a human rights-based approach requires states to develop policies that recognize citizens' entitlement to food security, and to design food systems that value and promote human dignity as a critical component of health and quality of life. Dignity as a specific dimension of food security has been understudied in food justice scholarship [5,11], and researchers have called for additional research regarding the critical relationship between dignity and food processes and practices $[11,12]$.

Our research broadly examines how structural inequalities and the United States' neoliberal approach to governance shapes the ways individuals construct a sense of dignity through daily experiences with food. Within the context of neoliberalism and structural inequality, we consider the development and implementation of rights-based local food access systems that prioritize and promote human dignity, despite neoliberal, advanced capitalist governments' failure to address structural inequalities as a root cause of food insecurity. Through qualitative in-depth interviews and ethnographic field study, we examine how individuals construct a sense of dignity through a range of food experiences and practices in a rural Oklahoma community with high rates of food insecurity. Our research contributes to growing literatures aiming to inform policies and strategies employed by community-led, rights-based food aid systems in advanced capitalist nations.

In the following sections, we first provide a brief review of neoliberalism and structural inequality in advanced capitalist nations, focusing on the United States. Next, we review existing literature on rights-based approaches and advancement of human dignity. We then offer a brief overview of the qualitative methods and analytic strategies we employ. Subsequently, we provide two sections of analysis, asking: How does structural inequality impact individuals' daily experiences with dignity construction? How is a sense of dignity influenced by daily experiences with food access and foodways within the context of community-based food initiatives? We close with a brief discussion of our findings and implications for future research.

\section{Literature Review}

Hunger and food insecurity are a direct result of structural inequalities developed through urban planning and zoning practices, inequitable distribution of wealth, and the commodification of food-the transformation of food into an object of trade expressed through economic value $[13,14]$. Wealthy, neoliberal nations, such as the United States, generally ignore structural inequalities as the root cause of food insecurity. Instead, neoliberal governments presume a deficiency in individuals' poor nutritional or household management or social and cultural capital, and develop responses based on consumerist models supporting "informed choice." Additionally, capitalist, neoliberal nations increasingly rely on the private sector to support social welfare needs and the market to regulate and manage food security [1]. Thus, capitalist states rarely recognize food security as a government's responsibility for maintaining public health, or as a guaranteed citizens right $[1,15,16]$.

Many food scholars and activists have called for a rights-based approach to food security - an approach that not only requires states to develop policies recognizing citizens' entitlement to food security, but also to design food systems that value and promote human dignity as a critical component of health and quality of life [1,8-10]. In the following sections, we review literature on the role that neoliberalism plays in propagating and reinforcing structural inequalities in food systems of advanced, capitalist nations. We then 
provide an overview of human rights-based approaches to food security and include a synthesis of interdisciplinary dignity literature to provide a theoretical framework.

\subsection{Neoliberalism and Structural Inequalities}

Neoliberalism is a political economic philosophy promoting individualism and a free-market system of governance premising little to no state intervention as the best means of advancing human well-being [17]. The emergence of neoliberalism among advanced capitalist nations in the 1970s, such as the United States and Britain, marked a shift from traditional forms of government-where the state alone held the power to regulate and manage economic and social conditions-to modern governance-a shared convergence of power between the state and private institutions [17]. Neoliberalism and capitalism are distinct concepts in theory, though inextricably intertwined in practice. Market-based neoliberal approaches to governance rely on the capitalization of social problems, such as privatization of civic and social services, like prisons [18] and healthcare [19], and the use of public-private partnerships for civic development and creating critical infrastructure [20]. In neoliberalism's market-based model, private institutions relieve the state of its social welfare responsibilities and influence legislation, public policies, and regulatory frameworks for their own benefit [17]. In his critique of US neoliberalism, Regilme asserts that "[n]eoliberalism has normalized routinized suffering, life-threatening inequalities, extreme poverty, and governments that are wholeheartedly willing to throw away huge amounts of money to save corporate behemoths rather than actual people's lives" [21] (p. 164). Thus, scholars argue the core problem of neoliberal governance is the resultant restoration of class power among wealthy capitalists and reproduction of structural inequalities [17].

Privatization also occurs outside the for-profit sector, where neoliberal governance relies on the charitable sector to manage the welfare state-such as feeding the food insecure through food aid-responsibilities formerly held by governments [20]. Roy critiques this political dynamic, writing, "It's almost as though the greater the devastation caused by neoliberalism, the greater the outbreak of NGOs" [22]. Shifting responsibility to provide a social safety net and maintain citizens' wellbeing from the state to the charitable sector presents challenges, in part, because private actors and institutions generally possess significantly less financial and human resources [20,23]. A more problematic consequence of institutionalizing the neoliberal ideology as a new public management style is likely the resultant shift in political discourse surrounding the rights of the most vulnerable. Neoliberal politics in advanced capitalist nations frame the presence of vulnerable citizens as a local issue rather than a national, systemic concern, diminishing the broad visibility of citizens' needs and portraying the most vulnerable as incompetent consumers of private goods rather than under-resourced citizens facing systemic barriers to accessing what was historically considered a common good [24,25]. At its core, neoliberalism in the United States ignores and perpetuates the existence of structural inequality, which food security advocates and researchers consider to be a primary impediment to creating a more just food system.

Many social scientists argue that neoliberalism not only defines America's system of state governance, but also current modes of food activism as well. Despite explicitly opposing neoliberalism in their discourses, many food activists promote market-based strategies that are characteristically less accessible to vulnerable populations, such as social entrepreneurship or buying particular brands and types of goods, rather than advocating for state responses aimed at dismantling structural inequality $[4,20]$. In response, a growing field of scholars and activists strive to reform existing food systems and address food insecurity using various means neglected by advanced capitalist governments' neoliberal approaches-emphasizing cultural relationships with food and the need for a food system to be built on human rights rather than capitalist relations $[3,10]$. The human rights approach has unique potential to underscore food insecurity as the symptom of a system that fails to ensure individuals and households have both adequate income and access to healthy, culturally appropriate foods [1]. Toward this goal, our research examines a 
cornerstone of rights-based approaches_the promotion of human dignity-exploring ways to integrate dignity promotion into existing strategies and practices to work toward a more just food system.

\subsection{The Right to Food}

A growing call among food security advocates for nations to emphasize "the right to food" as a basic human right has spurred research examining avenues for guaranteeing such a right to citizens $[1,9,26]$. The human right to food was first internationally recognized in the 1948 Universal Declaration of Human Rights (UNDHR) (Article 25) and subsequently enshrined in the 1966 International Covenant on Economic, Social and Cultural Rights (ICESCR), as well as in several regional treaties and national constitutions [27]. The human rights framework defines the right to food as guaranteeing that "every man, woman and child, alone or in community with others, have physical and economic access at all times to adequate food or means for its procurement" [28] (p. 2). The Committee on Economic, Social, and Cultural Rights also affirms that,

[T] he right to adequate food is indivisibly linked to the inherent dignity of the human person and is indispensable for the fulfilment of other human rights enshrined in the International Bill of Human Rights. It is also inseparable from social justice, requiring the adoption of appropriate economic, environmental and social policies, at both the national and international levels, oriented to the eradication of poverty and the fulfilment of human rights for all [28] (p. 4).

Thus, the right to food is inseparable from the guiding principle of the entire human rights system - that everyone is "born free and equal in dignity and rights" and should act towards each other in a spirit of fraternity [29].

The United States signed the Rome Declaration on World Food Security at the World Food Summit in 1996. In its official interpretive statements on the Declaration, the US "accept[ed] the provisions of the 'right of everyone to have access to safe and nutritious food' as an integral component of the right to a standard of living adequate for health and well-being, as set forth in the [UDHR] ..." " and acknowledged that all "measures by a State affecting food security must be consistent with the Charter of the United Nations and international law" [30]. Although the United States was integral in developing the UDHR and is a signatory to numerous covenants and treaties that include the right to food, the nation has yet to ratify any of those instruments and has failed to adopt human rights language in domestic legislation or regulation of the food system. In line with the nation's embrace of neoliberal capitalism, the United States has long supported a philosophy that the international human rights system refers primarily to rights inherent in individuals, requiring minimal state obligations. The US perceives its compelling national interest in the human rights regime as "foundationally based in military security and facilitating a neoliberal economic order upon which US capital and trade interests would thrive" [21] (p. 163).

In response, researchers urge food security activists constrained by neoliberal political environments to absorb the human rights framework's conception of humanity that premises equality and justice as a basis for human dignity [1,20,21]. As the cornerstone of the human rights system, dignity promotion must be an integral component of research or advocacy efforts toward reframing food security as a basic human right. According to Mann, the UDHR distinguishes dignity as "the prime principle, the wellspring and basis for universal human rights" [31] (p. 31). A better understanding of the relationship between dignity and food is needed to inform new practices and operations that can promote human dignity within existing market-based strategies and food aid organizations. Alkon asserts that although such strategies are imperfect modes of addressing both structural inequality and neoliberal modes of thought and governance, "such strategies may help to strengthen and inspire activists and supporters from many parts of the food movement to see the progressive possibilities beyond neoliberalism, and to create bridges to other forms of social justice activism" [20] (p. 31). 


\subsection{Defining Dignity}

To develop an empirical understanding of the link between food and dignity, dignity as a concept must be conceptually refined across disciplines. Early sociologists and many modern philosophers frame dignity as socially developed because it is contingent and contextual — shaped through social interaction and realized through social behavior $[32,33]$. Intertwined with both self and cultural identity [32-34], dignity may be earned or lost, promoted or violated, and is contingent on interactions, spaces, and historical patterns. As dignity is cultivated through social relations, its nature is fluid and changeable, yet self-defining and individually formative. Hodgkiss' review of dignity theories illustrates both the implicit and explicit ways several of sociology's founders-Marx, Durkheim, Weber, and Simmel—drew from philosophers, such as Kant, Rousseau, Poudhon, and others to "identify the modern human subject as the inevitable repository of 'dignity' itself the underlying essence of what constitutes 'the moral'" [35] (p. 418).

Unsurprisingly, classic sociologists centered the notion of dignity in social systems and processes, rather than considering dignity as an individualized concept. Marx focused on the inverse concept, indignity, or "the degradation or dehumanization of human beings," [36] (p. 42), arguing that capitalist social relations deny individuals certain autonomy and potential for self-actualization, resulting in violation of individuals' sense of human dignity. Similarly, Durkheim, Weber, and Simmel express ways in which human dignity can only be realized, lost, preserved, or promoted through social interaction. According to Hodgkiss, Durkheim stresses autonomy and freedom as prerequisites of dignity, concluding that, "dignity is itself contingent upon perception of 'the Other' ... The individual's perception of 'the Other' impacts on their own self-conception (dignity, thus, becomes a dialectical property)" [35] (p. 430). Both Weber and Simmel view dignity as a facet of developing a selfhood, only realized through social interactions and interactive comparisons of the self and others. In essence, dignity construction is primarily a function of social relations [35].

Structural inequalities in neoliberal, capitalist nations also aid in the creation of a dignity hierarchy of spaces and places. Laws and policies regulating access to certain spaces are increasingly representative of mainstream's antipathy toward those seen as "other" [37] (p. 730). As a result, underserved groups are often confined to social spaces that produce feelings of disenfranchisement and agency loss, which impacts dignity cultivation $[33,38]$. According to Jacobson et al., "[p]oor people and people who are otherwise socially marginalized are placed in vulnerable positions by ... the extent to which their access to resources is both geographically and politically limited (deprivation)" [37] (p. 728). Thus, dignity construction is inherently tied to an order of inequality, materializing in privilege and empowerment at one end, or racism, sexism, or spaces of abundant economic inequality at the other.

Other theorists consider how an individual cultivates dignity through a self-reflective process following exposure to a range of social experiences and contexts [31,38]. Miller and Keys found that a sense of dignity was either "validated" or "invalidated" for homeless individuals based on specific types of social interactions and events [38]. Jacobson et al. note that dignity can be established through explicit interactions where individuals receive either positive or negative verbal or physical responses from others [37]. In a study of homeless street people, Snow and Anderson find that individuals in lower ranks of status systems attempt to protect or enhance their sense of self-worth and dignity by displaying certain identity characteristics during social interactions [39]. Dignity can also be silently conveyed through social experiences and contexts that, upon self-reflection, impact individuals' sense of worth and personal value [31,38].

Berger and Luckmann assert dignity to be inherently entangled with identity [34]. Although dignity materializes in social contexts, it is dependent on how an individual is situated among the traditions and mores of a particular culture or society. Relatedly, Gewirth and Nordenfelt both conceptualize dignity as linked to self-respect and selfimage $[32,33]$. Nordenfelt centers dignity in the concept of identity and examines "the 
dignity we attach to ourselves as integrated and autonomous persons" [33] (p. 75). The dignity of identity is based on the desire to live autonomously and with agency, and thus can be socially altered when a person is implicitly prevented from living or acting in ways in which they feel they are entitled [33]. To this end, researchers find that certain aspects of the social world, such as historical processes and socially earned statuses attached to physical spaces, are inherently embedded in the process of dignity construction [33]. According to Parr, physical spaces are prime "arenas of identity formation in which individuals come to learn who they are through where they are" [40] (p. 226).

Explicitly defined rules and processes associated with certain social contexts and institutions can influence an individual's sense of dignity. According to Jacobson et al., institutions may exist for the purpose of distributing resources, "but the bureaucratic processes of application for and reception of these resources often are not designed to protect supplicants' feelings of worth or value" [37] (p. 728). Seltser, Jay, and Miller find that excessive rules and regulations at homeless shelters promote a general sense that homeless individuals cannot be trusted to manage their own lives or make their own decisions, leading those who rely on social assistance to feel incapable or unworthy of self-determination [41].

Additionally, associated aesthetics and stigmas of social spaces impact dignity construction through an individual's comparative understanding of the spaces they inhabit in contrast to the spaces inhabited by others. In a study of low-income individuals seeking healthcare, Jacobson et al. found that when people perceive themselves to be on the wrong side of certain spatial boundaries, such as living in low-income or environmentally degraded areas, they tend to see themselves as having crossed into personally debasing spaces [37]. Socio-spatial stigmatizations, as theorized by Goffman, can cause severe disjunctions between an individual's self-concept and their social identity; which, in turn, leads to a sense of dignity loss [42]. Additionally, in social spaces inhabited by diverse groups of individuals, structural inequalities and divisions between social classes are illuminated in the tacit use of status symbols and symbolic consumption [43]. Goffman theorized that individuals engage in a symbolic presentation of one's self by displaying certain status or class symbols to "influence in a desired direction other persons' judgment" as a means of constructing or preserving a sense of dignity [43] (p. 297). In a study of welfare recipients, Rogers-Dillon found that the stigma attached to using welfare assistance is "produced in the interaction of situation, social audience, and the recipient's life history," and had a significant effect on individuals' sense of identity and self-worth [44] (p. 453). Another study of welfare beneficiaries concluded that individuals' feelings of social acceptance, and consequently dignity and self-worth, varied based on whether the type and amount of assistance they received allowed them to purchase certain goods they perceived as desirable status symbols [45].

Synthesis of the inter-disciplinary literature on dignity reveals the multi-dimensional nature of the concept, providing an initial theoretical context for our project whereby dignity is understood as a social condition rather than individual trait. Dignity is cultivated, promoted, preserved, violated, and lost in a web of social processes embedded in the social structure, no more easily disentangled than the phenomena inherent in any other social condition. It is constructed through human connection and social integration. Most importantly, it is recognizable in the core of individual identity. Based on existing literature and emerging research-based concepts, we consider dignity to be related to positive feelings of pride, empowerment, honor, self-respect, self-identity, and self-worth; as well as negatively regarded feelings of shame, worthlessness, rejection, disregard, dehumanization, self-deprecation, and dishonor.

Researchers assert that restructuring the social order to promote fairness and equality "requires a theory of justice that privileges dignity as one of its guiding principles" [46] (p. 1084). Establishing an empirically driven framework of food and dignity can help inform new rights-based strategies and practices for food activists, and potentially propel food security toward ameliorative policy action. Therefore, this study explores the social 
construction of dignity through individuals' daily food experiences in a rural Oklahoma community to consider how community-led initiatives can adopt a rights-based approach to food security. We contribute a framework for researchers and activists working on food insecurity in advanced capitalist nations: (1) How does structural inequality impact individuals' daily experiences with dignity construction? (2) How is a sense of dignity influenced by daily experiences with food access and foodways within the context of community-based food initiatives?

\section{Research Design}

This piece is based on a case study of a mid-sized, rural, college town in Oklahoma with higher-than-average levels of food insecurity. As part of a community-based research project, authors collected data using (1) participant observation at local food pantries, community meal-sites, and community-organized meetings; and (2) face-to-face semistructured interviews with key stakeholders, volunteers, and community food program participants. Data collection occurred May 2016 to May 2018. The study locale was chosen based on several characteristics. USDA's state-level data notes that Oklahoma has the fourth highest rate of food insecurity in the country [7]. The study site county is consistently ranked in Oklahoma's top five counties for food insecurity, with an average rate of 20 percent of the population [47]. USDA measures highlight that a large portion of the rural county is situated in a food desert, with 58 percent of residents facing low access to healthy foods due to inequalities related to race/ethnicity, income, or lack of transportation [7]. Additionally, the county is home to one of the state's largest universities. Studies show that over the last decade college students have consistently suffered from higher rates of food insecurity than the average population $[48,49]$.

Although several organizations and civic agencies, including churches and service organizations, worked to improve food access for under-resourced residents over the last decade, most programs posed restricted access issues, with some available only one or two days a month, and most programs spread out across the county-making transportation a struggle. Thus, food assistance in the county has historically been characterized by a disjointed and inefficient approach. Multiple food assistance locations in the community also resulted in programs having less than necessary amounts of available food and other basic resources. During data collection, local-level community leaders, alongside the Regional Food Bank of Oklahoma, developed a new type of food access initiative. Called a Food and Resource Center (FRC), this initiative differed from existing traditional commodity and distribution methods, aiming to take a food justice approach. One of over a dozen centers in Oklahoma, the FRC's objective is to make food resources more widely accessible and available, to combine resources from multiple community programs, and offer the community a more centralized and efficient form of food assistance. By engaging with local food partners to support sustainable food access initiatives, offering educational programming, and a greater variety of food choices, the intent was to restore dignity to the process of food procurement for under-resourced individuals. High rates of food insecurity among residents in the rural community, issues of low food access, and the unique addition of university students living in the area, combined with a wide range of community food security operations and initiatives offered key opportunities for researchers to explore the ways in which community food aid can incorporate rights-based approaches to improving food security.

Our study is based on data from ethnographic field notes, semi-structured interviews with a sample of sixty-one participants, and archival data, including organizational documents and recorded videos provided by leaders and FRC board members. Purposeful sampling was employed based on the research questions and theoretical rationale from existing literature. All participants for the study fell into one of two categories, meeting criteria as specified: (1) Individuals over the age of eighteen, working in the broad arena of food support (e.g., board members of local food/poverty initiatives, employees and board members of local food pantries and resource centers, and volunteers with commu- 
nity assistance organizations); and (2) Individuals over the age of eighteen, living with food insecurity (e.g., those who self-identify as underserved members of their local food environment, those who are food insecure or experience issues related to low food access, or those who qualify for, and have used, food assistance through government or community programs). Interviewees were separated into in three groups, distinguished by the above-mentioned criteria.

Group One participants are drawn via snowball sample, recruited through referral whereby stakeholders participating in community food initiatives act as key informants to reveal connections to others involved with community food-work. Group Two and Three participants comprise an availability sample of individuals identifying as food insecure. Participants were recruited by word of mouth, invitation, and recruitment flyers. Although the study aimed for equal representation between groups and a diverse and representative sample of the greater population, some limitations exist due to a small pool of local respondents qualifying for Group One, and the self-identifying, voluntary nature of Groups Two and Three. Interviews were audio recorded and transcribed clean-verbatim. Participant demographics, broken down according to interview group, can be found in Table 1.

Table 1. Descriptives of full interview sample.

\begin{tabular}{|c|c|c|c|c|c|}
\hline \multicolumn{2}{|c|}{ Group 1 Participants; N=20 } & \multicolumn{2}{|c|}{ Group 2 Participants; N=18 } & \multicolumn{2}{|c|}{ Group 3 Participants; N=23 } \\
\hline Demographic & Participants & Demographic & Participants & Demographic & Participants \\
\hline Sex & & Sex & & ex & \\
\hline Male & 12 & Male & 7 & Male & 10 \\
\hline Female & 8 & Female & 11 & Female & 13 \\
\hline Race/Ethnicity & & Race/Ethnicity & & ace/Ethnicity & \\
\hline White & 20 & White & 11 & White & 18 \\
\hline Black & - & Black & 3 & Black & 3 \\
\hline Native American & - & Native American & 1 & Native American & 1 \\
\hline Hispanic & - & Hispanic & 2 & Hispanic & - \\
\hline Asian & - & Asian & - & Asian & 1 \\
\hline $\mathrm{N} / \mathrm{A}$ & - & $\mathrm{N} / \mathrm{A}$ & 1 & $\mathrm{~N} / \mathrm{A}$ & - \\
\hline Age & & Age & & ge & \\
\hline $25-35$ & 1 & $25-35$ & 4 & $25-35$ & 3 \\
\hline $36-45$ & 3 & $36-45$ & 3 & $36-45$ & 1 \\
\hline $46-55$ & 6 & $46-55$ & 6 & $46-55$ & 10 \\
\hline $56-65$ & 3 & $56-65$ & 2 & $56-65$ & 3 \\
\hline $66-75$ & 5 & $66-75$ & 1 & $66-75$ & 4 \\
\hline $76-85$ & 1 & $76-85$ & 1 & $76-85$ & 1 \\
\hline $\mathrm{N} / \mathrm{A}$ & 1 & $\mathrm{~N} / \mathrm{A}$ & 1 & $\mathrm{~N} / \mathrm{A}$ & 1 \\
\hline Education & & Education & & ducation & \\
\hline Less than High School & - & Less than High School & 1 & Less than High School & 7 \\
\hline High School Diploma & 1 & High School Diploma & 6 & High School Diploma & 6 \\
\hline Some College & 3 & Some College & 7 & Some College & 6 \\
\hline Bachelor's Degree & 6 & Bachelor's Degree & 2 & Bachelor's Degree & 3 \\
\hline Graduate Degree & 10 & Graduate Degree & 1 & Graduate Degree & 1 \\
\hline N/A & - & N/A & 1 & N/A & - \\
\hline Income Level & & Income Level & & ncome Level & \\
\hline Less than $\$ 15,000$ & - & Less than $\$ 15,000$ & 10 & Less than $\$ 15,000$ & 12 \\
\hline$\$ 15,000-\$ 29,999$ & 1 & $\$ 15,000-\$ 29,999$ & 6 & $\$ 15,000-\$ 29,999$ & 7 \\
\hline$\$ 30,000-\$ 44,999$ & - & $\$ 30,000-\$ 44,999$ & 2 & $\$ 30,000-\$ 44,999$ & 4 \\
\hline$\$ 45,000-\$ 59,999$ & 2 & $\$ 45,000-\$ 59,999$ & - & $\$ 45,000-\$ 59,999$ & - \\
\hline$\$ 60,000-\$ 74,999$ & - & $\$ 60,000-\$ 74,999$ & - & $\$ 60,000-\$ 74,999$ & - \\
\hline$\$ 75,000-\$ 89,999$ & 3 & $\$ 75,000-\$ 89,999$ & - & $\$ 75,000-\$ 89,999$ & - \\
\hline$\$ 90,000-\$ 100,000$ & 3 & $\$ 90,000-\$ 100,000$ & - & $\$ 90,000-\$ 100,000$ & - \\
\hline More than $\$ 100,000$ & 10 & More than $\$ 100,000$ & - & More than $\$ 100,000$ & - \\
\hline N/A & 1 & N/A & - & N/A & - \\
\hline
\end{tabular}


As part of a larger project, authors designed the interview guide to elucidate concepts related to organizational development and the community food environment. Interviews approached central themes of dignity through a series of questions drawing out participants key memories, practices, and experiences with food, and encouraging further exploration into individuals' feelings associated with food access, food sovereignty, and foodways. Data were analyzed using NVivo 11 and 12. We employed a qualitative content analysis (QCA) strategy, a common data analysis approach used to systematically describe and ascertain meaning in qualitative data, as defined by Schreier [50]. Codes were generated through a part data-driven and part concept-driven process. Through the use of open coding and memo-writing, theoretically driven concepts were identified and coded into the core category, or 'node' of "Dignity." Based on existing literature, narratives were coded into the "Dignity" category if they centered on either positive connotations related to dignity, such as pride, empowerment, self-identity, self-worth, or honor; or, if they centered on negative connotations related to dignity, such as shame, worthlessness, insignificance, disenfranchisement, dehumanization, self-deprecation, or dishonor. All data within the "Dignity" node were analyzed using a line-by-line coding strategy, and exhaustively coded into mutually exclusive sub-categories based on emerging conceptualizations of dignity construction occurring in varying social arenas.

All transcripts were read and coded, with a portion of transcripts coded by an additional independent researcher, to ensure an inter-coder reliability rate of 90 percent or greater. Key themes and conceptual categories were agreed upon through discussions and analysis of transcripts. As suggested by Corbin and Strauss, transcripts and findings were returned to participants to validate assessments [51]. Participants were offered an opportunity to release their audio-recorded interviews for archiving with the Oklahoma Oral History Research Program, where interviews and transcripts will be accessible to the public, as well as for future research. Clean verbatim extracts from the interview transcripts are presented to illustrate findings.

\section{Findings}

Governance strategies in advanced capitalist nations perpetuate broad neoliberal social narratives that reinforce structural inequalities. In such political environments, a social hierarchy of food security is created, whereby individuals occupying higher positions of the hierarchy experience food security, and those who occupy lower positions in the hierarchy suffer deleterious effects of food insecurity. The social hierarchy of food security is maintained through key aspects of structural inequality, particularly class divisions and constraints to opportunities, which facilitates individuals' daily food experiences. We explore the social construction of dignity through individuals' daily experiences with food access and foodways. Our goal is to provide insight into community-led food aid, aiming to develop local systems that prioritize and promote human dignity and the human right to food, despite advanced capitalist governments' damaging 'hands-off' approach and failure to address structural inequalities.

In the first analysis section, we broadly examine how key aspects of structural inequality and the resultant social hierarchy of food security, serves as a basis for defining individuals' daily, lived experiences, thus influencing dignity construction. In the second section, we organize individuals' daily experiences with food into three distinct social arenas - relational, individual, and institutional, and explore how individuals' sense of dignity can be promoted through food experiences within each arena. In reality, daily experiences in the social world overlap between two or more of these arenas; however, we present the three arenas in this paper as distinct, analytical constructs. We organize individuals' daily food experiences within a particular arena based on conceptualizations provided by participants themselves. 


\subsection{Structural Inequality and Daily Experiences of Dignity Construction}

While structural inequality is rarely explicitly recognized, participants acknowledge that a social hierarchy of food security exists and offer a general admission of their position within that hierarchy. Key structural forces, such as class division and constraints to opportunities, underlie beliefs, judgments, understandings, and actions that impact one's sense of dignity. As noted by both Bedore and Caruso, class division into differing social strata perpetuates victim-blaming social narratives, frames issues related to food security as individual rather than structural, and propagates the idea that personal choices and actions of the food insecure are the sole contributing force to their position $[5,11]$. This aligns with Harvey's observation of neoliberalism's role in maintaining structural inequalities and class power dynamics [17]. Discussing what he believes to be the underlying cause of food insecurity, a former government official and prominent civic leader states,

In all shape or forms, it rolls back to economic possibilities and economic conditions. I'm not talking macro-economics on this, I'm talking about that individual person and the decisions that they need to be making. Food scarcity and decision making go hand-in-hand ... I don't want to sound elitist or superior as I say this, but there's a way to teach a different type of thought process to try and break that immediate gratification of what it appears from the outside to be the must-have thing, and roll it back to necessities for when you need necessities.

Understanding victim-blame dimensions of structural inequality is crucial to understanding dignity construction. Structural inequality acts to preserve a sense of dignity and self-worth for food secure individuals, while simultaneously degrading under-resourced individuals by blaming them for their own misfortune and inability to access nutritionally adequate food and other basic needs. A long-time community volunteer and member of the FRC Operations Team describes this notion,

People from the outside would say, 'Well I've thought of volunteering at [the food pantry], but when I see them pull up and stand outside waiting for the doors to open and they're smoking cigarettes. I think that $\$ 60$ a carton, that could go toward food.' ... But, that's not a reason to say, 'I'm not going to serve these people because I don't agree with the way they spend their money.' ... You tell yourself stories so that you don't see what you don't want to see. I think maybe the people who would say, 'Well I can't volunteer there because I can't justify all of the luxuries those people buy when their children are starving,' that's just another story people tell themselves so they can sleep at night.

A prominent community organizer and leader in the emerging FRC, notes that the organization struggled to galvanize community support during development due to community-wide feelings of distrust. When asked if she was referring to a "distrust of the system," she responded, "Not the system, but of the persons using the system." In line with both Hasenfeld and Garrow's and Jones et al.'s assertion that neoliberalism frames the vulnerable as incompetent consumers, this perception was echoed across all interview phases $[24,25]$. Participants at all levels of the social hierarchy overwhelmingly noted a socially pervasive idea that under-resourced individuals are "taking advantage of resources" or "gaming the system." A long-time manager of food pantries and other food assistance programs states,

There's myths out there about people who go to food banks. I like to try and break those myths as much as I can. For example, 'Everyone takes advantage of food stamps.' Or, 'A lot of people on food stamps just waste their money.' When you look at the statistics, it's a very, very, very low percentage of people that actually take advantage or misuse it. Most people in the gap don't qualify, or don't qualify for enough.

As noted by Hasenfeld and Garrow and Jones et al., the pervasiveness of neoliberal ideology in the United States results in class-based misperceptions and ideas at society's 
structural level, which underlies the absence of large-scale resolutions to adequately address food insecurity and other issues related to structural inequality [24,25]. Perhaps the most critical aspect of social misperceptions, is understanding how neoliberal ideologies of individual-blame perpetuated by class division acts as a veil, shielding society from recognizing structural forces that maintain a social hierarchy of food security and act as a barrier to food access.

\subsection{Dignity and Daily Experiences with Food Access and Foodways in the Context of Community-Based Food Initiatives}

Human dignity, understood as a universal property or social condition, is fluid and exists concurrently within multiple social arenas. When discussing experiences related to the cultivation or preservation of dignity, individuals perceive events to occur in three social arenas-relational, individual, and institutional—with overlapping experiences between the arenas.

\subsubsection{Dignity Construction in the Relational Arena}

The relational arena envelops individuals' daily life experiences related to social encounters. In this arena, social encounters linked to food experiences take two primary forms. First, social misperceptions and judgments regarding the food insecure, facilitated by division of classes in the social hierarchy of food security, emerge during social encounters. Second, class divisions and separations in the social hierarchy facilitate social bonding and "belonging" within classes, and perpetuate "othering" between classes. Regarding specific types of food experiences, individuals' interactions with food access have the strongest influence on the social construction of dignity in the relational arena.

Food access experiences in the relational arena primarily took the form of social encounters between individuals and others during food procurement processes. Participants differentiate between encounters characterized as "treatment" and those characterized as "interactions." When asked how they are "treated" in grocery stores, all participants found it difficult to recount experiences that bolstered a sense of dignity. Participants either confusedly state they are treated "fine" or "okay, I guess," or they begin discussing encounters that degrade their sense of dignity. Conversely, when asked to discuss or describe the "interactions" they have in grocery stores, participants are much more likely to describe experiences that elevate their sense of dignity. This is an important distinction in terminology, as "treatment" infers an asymmetrical social encounter, with both a subject and object; whereas, "interaction" suggests a more symmetrical engagement. This finding reaffirms Jacobson et al.'s assertion that the level of symmetry between actors in social interactions directly influences the cultivation of individuals' sense of dignity [37]. Class divisions perpetuated by structural inequality underlie the distinction between "treatment" and "interaction" in the social construction of dignity.

Individuals describe their sense of dignity as being promoted or enhanced in interactions during processes of food procurement with individuals occupying similar social hierarchy positions to themselves. Individuals describe how social encounters promote social bonding or a sense of "belonging." The cultivation or preservation of dignity is evident in the ways that individuals recount experiences-expressing gratification for connecting or bonding with others during such processes.

Participants describe food sites, such as grocery stores and food pantries, as the primary grounds of the relational arena. In these spaces, individuals report a variety of social interactions that promote dignity, ranging from simple recipe exchanges to developing friendships and relationships continuing outside of food spaces. For some, deciding where to access food is based, at least in part, on expected interactions. A sixty-seven-year-old retiree discusses how he chooses which local grocery store to visit. He mentions the local IGA as his favorite. When asked why, he responds,

It's just the atmosphere. The people were quite friendly, and the lady at the checkout always checked your eggs to see if there were any cracked eggs. The 
owner was right there and he would push out the cart if you needed ... and take the groceries to your car, and I liked that.

Rather than focusing on products or location, what makes this his preferred grocery store is his interactions with the owner and employees. A sixty-six-year-old woman echoes this sentiment, "I like when I go into my grocery store. They might not know my name, but I'm familiar to them, there's a sense of recognition, helpfulness. I don't mind standing in a long line if someone's reasonably polite-not just polite, but pleasant; and just with you in the process." For individuals across the food security spectrum, there is a sense that the places one goes to get food are the center, or "the heart" of the community. Individuals note interacting with friends, neighbors, and colleagues in these spaces. One woman, who maintains a regular Saturday grocery shopping schedule, discusses how going to the grocery store often turns into a social event. She notes,

Because we go almost every Saturday morning we see the same people, we see couples from our Sunday school class ... so, that kind of becomes a little bit of a social time as well. [Laughter.] ... We'll look at each other's basket and go, "Ooh, that looks good," or, "Ooh, these are on sale." We will talk and compare and share recipes.

The idea of accessing food as a social event is also illustrated by individuals' accounts of visiting the local farmer's market. A thirty-nine-year-old mother to three maintains that her interactions at the farmer's market are characterized by developing social connections with others who shop and sell goods there. "I love the fresh, clean air, and visiting with people who grew stuff! I have a garden in the backyard so I love to learn from them. Like, 'When do you cut your asparagus?' because I just planted some, or 'When should I plant that?' I like the visiting aspect!" Another woman in the community discusses her interactions at the farmer's market as a means of recognizing and maintaining a sense of community, "I think it's just a fun experience to shop out in the open and to see people that have grown a product-it's a community feeling to me. The farmer's market is more than food shopping ... I appreciate what they've put into it, and respect it ... I enjoy the people that are there".

Importantly, the sense of belonging developed through social interactions in food spaces is not uniquely experienced by those holding higher positions in the social hierarchy of food security. While food secure individuals' experiences are more likely to be in spaces stigmatized as middle-class or white, such as the farmer's market, individuals who are food insecure report a sense of social bonding and connection through interactions in local food pantries, the FRC, and at community meals. When asked about interactions at food aid sites, almost all participants recounted social interactions that promoted community bonding, and in return, elevated their sense of dignity. As noted by Mann and Miller and Keys, participants discussed a self-reflective process, whereby interactions with others accessing food in these spaces preserved or promoted their own sense of dignity [31,38]. A thirty-four-year-old single woman explained how these interactions helped her overcome the negative stigma associated with using food aid,

You get to talk to people ... you get to spark up a conversation, it passes time.

I ran into people here that I didn't know needed it. And you walk in this door, you think-there's a stigma needing something like this-you think that you're a horrible person having to be at this level. And then, you walk in here and find people you know.

Likewise, a sixty-eight-year-old woman who has used food pantries off and on throughout her life mentioned that the pantry she visits has a "good community feel to it," noting, "You see people there that you know. You can interact, visit." Participants living alone mention that community meal sites and food pantries provide a sense of belonging they would otherwise lack. A forty-eight-year-old single man states,

I'll go there to the [community meal] sometimes just to have something to do. I'm a loner. I hang out in my room a lot ... or my apartment. Some of the neighbors 
there that I get along with... I go down there just to associate. I got friends that go down there along with me that I've known for a while who are poor, too, and could use a good meal. We'll go down there and we'll eat and hang out.

Similarly, an eighty-four-old-retiree explains that he and his father have attended area community-provided meals for years, sometimes out of need for food, and sometimes simply because they "enjoy the fellowship so much." In fact, almost every participant using food assistance programs in the area claims they have built meaningful relationships with others who go to pantries and community meal sites to access food,

I just meet [people] there. It's a very social group for the most part. We see each other every time we go! It's a community. It's a lot like the homeless community in a sense. And, there's a community involved in people that use the food banks. Once you get over the shame of having to go to a food bank, and you know all those people are in the exact same situation, then you talk and find out, and you ask questions. A lot of people are like me. And, you'll see little groups swapping out in the parking lot. If you want to see something, wait about five minutes after it closes and go see the swap shop. [Laughter.]

When characterized by symmetrical social encounters, interactions with others in food access spaces allow individuals an opportunity to develop social connections and a sense of belonging that promote greater constructions of dignity.

\subsubsection{Dignity Construction in the Individual Arena}

The individual arena encapsulates daily experiences cultivating or maintaining selfidentity with individuals as the primary actor. Individuals' sense of dignity is influenced by being either confined or privileged to particular life chances or opportunities. As the result of structural inequalities, maintained through neoliberalism, daily food experiences in the individual arena are characterized by available or unavailable opportunities based on one's position in the social hierarchy of food security.

Similar to findings by Alkon and Norgaard (2009) and Hauck-Lawson (1998), participants regard food as an implicit component of both their individual and cultural identity. Berger and Luckmann, Gewirth, and Nordenfelt, note that dignity is inextricably attached to one's sense of identity [32-34]. In the individual arena, daily experiences with foodways, in particular, influence the social construction of dignity through developing or diminishing one's sense of identity or self-concept. Experiences are characterized by attachment to foodways and personal meanings individuals ascribe to foods. Participants illustrate the attachment by expressing the ways they recognize self-identity in food practices and cultural traditions. Every participant reported an elevation of their sense of dignity when permitted to engage in foodways they deem important. Dignity is promoted or enhanced in the individual arena through experiences with two fundamental aspects of foodways: cultural or familial traditions and the act of role-taking as a food provider. Participants, regardless of their position in the social hierarchy of food security, discuss traditions related to food crucial for cultivating and maintaining identity and dignity. For some, traditions revolve around holidays and family gatherings. For others, certain recipes or foodways are engrained in family or personal histories. As noted by Berger and Luckmann, observing and participating in traditional foodways serves as a connection to uplifting memories and human bonds [34]. A fifty-one-year-old woman stated that she felt a sense of pride in passing down cultural traditions to children, stating, "Gotta keep the culture!" She explained the importance of food traditions as a way of teaching cultural history,

I love my African-American-slash-Indian roots. Having African-American childrenthere's a lot to be told. I don't want it to go away. It's always been important to me. Two or three years ago when there was race wars-it helped that my kids understood what was going on .... Especially when you have get-togethers like Mother's Day or fourth of July and you're gathering around, and you're talking, and you're eating, and you're explaining. 
Family attachment and connection to others is a primary form of cultivating dignity. Participants recount learning how to cook and prepare food from family members or loved ones, and report pride in that connection to familial cultural identity. One fifty-year-old man notes that he enjoys cooking for others because he feels cultural pride in the foods he prepares. When asked how he learned to cook, he responds, "Home-cooking from my mom and grandma, Mexicans, because I was around them for quite a while. The other is just reading and experimenting because I enjoy it. I don't eat a lot, but I like to cook for others ... [I enjoy] watching them smile because they've never had it before".

For many, culture is significant in developing foodways. Food serves as a vehicle for cultivating, maintaining, and passing cultural identity to children and others. This was most evident when individuals discuss merging cultural traditions with partners. One woman explains the ways that her cultural identity with food differs from her husband's, discussing how they have engrained food traditions into their family's foodways,

My husband is black. I learned their types of foods ... I had never had greens in my life. I never had chitterlings... I never had ANY of those types of foods. It's totally different, and yes, a little bit cliché, because for Thanksgiving, it's fried chicken, [laughter], and all these greens. Where I grew up, my dad and I would hunt our turkey. At Thanksgiving, we compromise ... We do a mixture. I do my foods, and sweet potatoes. He makes his greens. So, we cook together Thanksgiving dinners, and Christmas dinners, and Easter ... We've made our own memories.

Mentions of foodways are prevalent in discussions surrounding cultural holidays and food traditions. Participants view these events as an opportunity to develop their own food practices, which cultivates personal and familial identity. A forty-six-year-old father of two illustrates the ways their family maintains an inter-generational family identity through Christmas traditions,

When I say tradition, what I mean is my mom used to always fix lasagna. That was our Christmas dinner. I couldn't even begin to tell you why. That's what she would do. She passed fourteen years ago. My kids were real little. I bet you can guess what we have for Christmas dinner at my house now! That's where I see the comfort side of it, [as a connection to other people].

The permanence of foodways, and individuals' aversion to stray from tradition illustrates their embeddedness in individuals' lives, and the recognition of selfidentity and a sense of dignity that follows.

Individuals also discuss foodways rooted in day-to-day family practices and experiences. In response to questions regarding "foodways that are important to you or your family," or "types of foods or practices that you strongly identify with," participants were quick to recall memories engrained in personal histories. Spending most of her life living on a lower income, a grandmother's foodways were constrained by her position in the social hierarchy of food. She articulates how being in a food insecure position, financially and socially, presented her with opportunities to use certain foods, such as boxed macaroni and cheese, to develop family traditions and identity,

My ex-husband would only give me twenty bucks a month for groceries ... the kids face when I'd pull out the macaroni and cheese - that's a HAPPY memory. To this day, the kids will still call me up, and they'll say, 'Mom, can you make macaroni and cheese and barbecue chicken?' [Laughter] I mean, the oldest one is twenty-seven.

Years later, she remains attached to this foodways as a form of both memory and identity. As many others in her position note, on days when she feels particularly "down" or "bad about herself," she turns to these fond memories as a means of elevating her sense of dignity. "You know, that's good memories. When I want to experience my memories, I go eat the food". 
Participants also perceive dignity to be promoted or elevated through recognition of their role as the food "provider." In line with Nordenfelt's assertion that dignity is attached to an individual's ability to live with autonomy and agency, participants noted that the ability to make food available for their families, and to do it in ways they deem desirable, fosters a sense of achievement or pride [33]. One woman recounts a long list of traditional foodways performed by her family that are her "favorite things," such as her aunt's broccoli casserole at Christmas, her grandma's homemade pickles and apple butter, and the way her grandpa makes his waffles. When asked why she sees those things as definitive aspects of her family, she becomes emotional, tearfully responding, "Food is an important staple ... . A holiday, or any kind of family gathering, you bring food. It's like the ultimate gift of love to be able to provide that, you know? To nourish your family".

In conversations and ethnographic observations surrounding the notion of being "the provider," participants were often visibly expressive, signifying deeper emotional and social meanings attached to food. A sixty-year-old-man, who battles hunger daily, states that he takes pride in cooking and providing for others. He notes, "It's a gift. It's a blessing. Knowing that you're actually helping someone take another step for another day ... It's just something I've always liked to do." For many, providing food for others encompasses more than nutrition or basic sustenance. Instead, providing food is a way of elevating both their own, and others', sense of dignity. When asked how it makes him feel when he is able to provide his children with foods they like, or foods that make them happy, a father to four who struggles with daily food insecurity responds, "It makes me feel like the world!" A twenty-eight-year-old college student explained that he takes pride in studying certain food's healing properties and being able to provide those foods to others,

Giving someone quality food that also tastes good is important to me. Knowing it is also going to help their bodies and not just give them comfort- "Hey, I put some cloves in this, and some cinnamon, and some allspice, and this is going to clean out your colon." [Laughter.] With so many ailments that are rising up today ... a lot of these ailments can be assisted or cured by food, or herb, a leaf from a tree, tree bark.

Participants note the empowerment that comes from being able to provide for themselves and others. Taking the role of "the provider" elevates one's sense of dignity, cultivating pride and self-worth. One young man explains, "I think it's human nature to have dignity or pride to get food, especially when we actually hunt food because you went out there to hunt, you got it! You brought it home to the family. It's a sense of accomplishment." A mother of two reaffirms this notion, expressing a sense of pride in her ability to manage resources and provide food, "If the world crashed right now, I can hunt, I can fish, I can skin my own stuff, and I can survive!" Achieving in the role of "provider" is critical to dignity construction.

\subsubsection{Dignity Construction in the Institutional Arena}

The institutional arena encapsulates daily experiences with organizations, agencies, and government programs where individuals perceive the basic structures, processes, and practices of institutions to impact their sense of dignity. Whereas the relational arena centers on experiences with food access and the individual arena primarily encompasses foodways, we find that the institutional arena influences dignity through experiences related to both food access and foodways. In this arena, experiences that influence dignity in the former two arenas are legitimized as practices, rules, and regulations. Individuals struggling with food insecurity perceive organizational structures, practices, and processes to influence dignity in two primary ways. First, sense of dignity is impacted by the basic structures and operational strategies of institutions. Second, dignity is influenced by individuals' ability to volunteer or provide some form of aid at community food programs and agencies.

Participants mentioned several dimensions of institutional experiences in the structures and strategies of community food aid that influenced a sense of dignity, including the physical space, layout, location, available times, and an emphasis on choice in the shopping 
experience. A guest at the FRC noted how the space itself impacted her experience with accessing food, "The building is amazing. I would have never dreamed that ... wow. They have really done a great job. It doesn't feel overwhelming." Another guest of the new FRC contrasted the physical space of the new facility with her experiences at some of the older food pantries in the area, "It's not nasty, you know. A lot of the food banks are in some kind of old, small, gritty, kind of dirty place. It just makes you feel nasty ... I'm really glad that it's so organized and clean. It doesn't stink".

Participants also described specific layouts and operational strategies of community food aid sites that elevated their sense of dignity. Importantly, all participants note that the newer food aid models, where the experience closely replicates shopping at a grocery store, felt more "humane" and "personable" than food pantries with traditional distribution methods that often made them feel "like just a number," and "less like a person." Explaining how newer models are more respectful of her and her time, a thirty-two-year-old woman stated, "I just feel like it's less like herding cattle ... versus having a stall that they go into and graze. And I know that that's very simplistic. But you do kind of feel like you're a person. You know that you're not just I'm-here-and-I'm-hungry kind of thing".

While many food agencies require significant paperwork and evidence of need, the FRC does not. The agency's director notes,

We don't require our guests to prove their income. If someone is willing to come here and actually ask for food assistance, that's a humbling enough process. I don't want to create extra barriers to prevent someone from accessing food. We've chosen not to require someone to prove to us their income. That's been something that a few people have mentioned is 'how do you know people aren't lying?' Well I don't. But I'm hopeful that they're not ... . I have people who come in here just won't even look me in the eye, because they're embarrassed that they have to get food. I just think that the myth that everyone's going to lie about it just so they can get free food is false.

While Seltser, Jay, and Miller's research focused specifically on homeless shelters negatively impacting dignity through excessive rules and regulations, participants reported the same experience with community food aid programs [41]. Participants who have used both the FRC and other food pantries in the community noted that the FRC's simple registration process helped to alleviate some of the barriers to food access that they felt at other sites. One woman reiterated this point when explaining how she has influenced others to try the FRC who had previously felt reluctant to use food aid, stating, "All you have to do is bring a driver's license and show where you live on a bill. Fill out this paperwork-easy breezy lemon squeezy. I think a lot of people just don't understand how rewarding and easy it is, if they just took that first step." Additionally, unlike other food pantries in the state run by churches, that necessitate prayer in exchange for food access, the FRC model also does not require religious practice to acquire food. One participant, a grandmother and caretaker of children notes, "We don't have to pray, and we don't have to do any of that. It feels like going grocery shopping. It really does." The relaxed requirements regarding paperwork and religious practice help to enhance a sense of dignity in food access.

Institutional practices respecting foodways in community food aid are dignity enhancing as well. In the FRC model, guests are guided by volunteers and encouraged to take items they will use in their households rather than being required to take food they may not use. The director states,

The big difference is that we're client-choice, so we're set up to look like a grocery store. But everything's free ... We do that because it increases dignity for our guests, whenever mom is choosing the food she wants to feed her kids instead of just going and getting a box of food that we want to feed her kids with, or we think her kids should eat. There's just dignity in the process of choosing the foods for yourself and for your family. It also reduces waste. If you get a box 
of American cheese, and pasta, and tuna but the family hates tuna-the tuna then goes in the trash. Here, you can choose peanut butter instead of tuna ... . It creates more options. The main thing is that it gives a lot of dignity to the family that's choosing the foods that they want to eat.

Supporting Jacobson et al.'s assertion that institutional processes for distributing resources can impact supplicants' "feelings of worth or value" [37] (p. 728), every participant who has used community food aid stated that operational strategies that offer a choice in the types and amount of food they receive significantly enhanced their sense of dignity. One woman, retired and in her 80 s, reflects,

I really do like the way they do it now. Used to you walked in, you took a number, they called your number, they gave you three or four sacks full of groceries and half of the stuff that was in there you couldn't even use. Or you didn't like. We shared it with other people that liked whatever we got. This way, we can go up and down the aisle just like we do in the grocery store, and we can pick up exactly what we like, and what we will use. And if there isn't anything I'll use, I won't take it. The way they do that is so much better than what they used to be at the food banks.

As posited by classical sociologists, such as Marx and Durkheim [36], and Nordenfelt [33], the elevation of individuals' autonomy and agency inherent in client-choice models of community food aid promotes a sense of dignity among those accessing food at such institutions.

At the community-level, all food assistance programs-both food pantries and mealsites-rely on volunteers for operation. Community members volunteer, including those who use services and those who do not. While experiences of community volunteers who are not using services are generally reported as positive, they are rarely framed as dignity elevating. For individuals using services, volunteering offers a sense of empowerment, and positively impacts their sense of dignity.

For many, giving back alleviates some of the shame they feel from service reliance. One woman who has benefitted from food pantries and homeless shelters throughout her life notes, "I like being a part of helping people. And also, [I like] to let them know I'm not just taking all the time. It's a way to give back." This was a common theme among participants expressing a desire to help at places in the community. For others, volunteering is a way to cultivate a sense of community into the pantry. This is especially true at one church-run pantry. Here, some of the pantry guests, who also volunteer, use the church kitchen to cook breakfast for all helpers on food distribution day. The director explains how they all eat together before opening, which creates a strong sense of community among guests and volunteers, with everyone working together toward a common goal. With this practice, guests of the pantry also gain a sense of ownership in the organization, helping to enhance pride and dignity in the work they do. Similarly, a forty-eight-year-old woman, who both received food from a community pantry and volunteered at the pantry for several years, notes how being a part of the volunteer group gives her a sense of purpose,

I feel like I'm not just a body. I feel like I'm a part of the team ... Getting a bond with other people is important to me because I'm a people person. I'm not just a person that's, 'Oh, well, I'm getting this free.' No. Give me something to do. Let me help out! [If] you're able to, at least give something back to the community.

Institutional structures that are designed to be aesthetically pleasing, offer choice to support foodways, and invite engagement via volunteer opportunities and the chance to give back promote an individual's sense of dignity.

\section{Discussion and Conclusions}

Structural inequalities in advanced capitalist nations are a central impediment to achieving food security for all individuals. Within a neoliberal framework, characterized by victim-blame approaches, a social hierarchy is established and reproduced by food 
processes and practices. Social inequalities exist between those who suffer injurious effects of living with food insecurity and those privileged to live with food security. By exploring individuals' daily experiences, aspects of structure in advanced capitalist nations are found to act as prime mediating factors of social constructions of dignity. The United States' neoliberal approach to governance shapes the ways individuals construct a sense of dignity through daily experiences with food.

Individuals perceive experiences related to the cultivation or preservation of dignity in the food system to occur in three particular social arenas-relational, individual, and institutional. Social judgments regarding the food insecure, facilitated by division of classes in the social hierarchy of food security, emerge during social encounters. Class divisions and separations in the social hierarchy facilitate social bonding and "belonging" within classes, and perpetuate "othering" between classes. In the relational arena individuals" interactions with food access have the strongest influence on the social construction of dignity. Regardless of position in the social hierarchy, interactions with others in spaces and places of food access are likely to promote dignity if interactions are characterized by symmetrical social encounters. In symmetrical experiences, individuals are able to develop social connections and a sense of belonging, influencing the resulting social construction of dignity.

Constraints to opportunities within the individual arena, determined by one's position in the social hierarchy of food security, mediate daily experiences with foodways, and either restrict or encourage individuals' agency and ability to practice foodways critical to developing identity and a sense of dignity. Daily experiences with foodways influence the social construction of dignity through developing or diminishing individuals' sense of identity or self-concept. Attachment to foodways and personal meanings individuals ascribe to foods characterize experiences. Participants recognize self-identity in food practices and cultural traditions and report an elevation in sense of dignity when permitted to engage in foodways they deem important. Dignity is promoted or enhanced in the individual arena through experiences with cultural or familial traditions and the act of role-taking as a food provider.

Encapsulating daily experiences with organizations, agencies, and government programs, the institutional arena is where individuals perceive the basic structures, processes, and practices of institutions to impact their sense of dignity via experiences related to both food access and foodways. Dignity in this arena is impacted by the basic structures and operational strategies of institutions and by individuals' ability to volunteer or provide some form of aid at community food programs and agencies. Of all three social arenas where individuals perceive daily experiences to impact their sense of dignity, we find that the institutional arena provides the most visible display of how daily experiences with dignity cultivation are facilitated by structural inequality. It is in this arena where individuals are most likely to recognize food insecurity as a systemic issue that must be confronted at the structural level. The concept of dignity is a critical component of human rights; but also, as a social condition, dignity is a key indicator that points to larger structural deficiencies and inequalities that must be confronted before any form of justice can be achieved. As noted by one woman, through heavy tears, "We're all just humans, you know. We're all just trying to make it. And in a system that is flawed, severely, in all different kinds of categories, I feel like they're setting us up for failure ... In a broken system, they set you up for failure".

Our findings indicate that solutions-based approaches to promote dignity through practices and policies can be found in all three social arenas. At the relational level, active efforts to promote symmetrical social encounters in accessing food, whereby all levels in the social hierarchy of food security are treated with respect, are able to develop social connections, and individuals feel as if they belong in food access places and spaces are central to promoting dignity. In the individual arena, opportunities to enhance agency and practice foodways are important to developing identity and a sense of dignity and should be encouraged. Emphasis on cultural or familial traditions and the act of role-taking as 
a food provider without judgement or stigma is central. At the institutional level, basic structures and operational strategies of institutions, including clean and pleasing spaces, easy to maneuver policies and procedures as well as opportunities to volunteer or provide aid at community food programs and agencies are important for dignity construction and maintenance.

The case study nature of the project presents limitations to generalizability, yet daily experiences of dignity construction reported by individuals relate directly to theoretical notions previously considered by other scholars, are affirmed in prior studies of similar circumstances, and help bolster the robustness of our findings. The concept of dignity has been largely understudied in food justice and security scholarship. Intended to fill this research gap, our study reveals the crucial relationship between human dignity and food processes and practices, considering rights-based local food access systems that prioritize and promote human dignity, despite neoliberal, advanced capitalist governments' failure to address structural inequalities as a root cause of food insecurity. By building an understanding of the dignity-food relationship developed in this project, food justice work can begin to restructure the social order at a societal level to promote fairness, equality, and a greater sense of dignity for all individuals, regardless of their position in the social hierarchy of food security.

Author Contributions: Both authors have contributed equally to the manuscript. Both authors have read and agreed to the published version of the manuscript.

Funding: Partial funding for this project was provided by the Oklahoma State University College of Arts and Sciences Community Engagement Grant Program.

Institutional Review Board Statement: The study was conducted according to the guidelines of the Declaration of Helsinki, and approved by the Institutional Review Board of Oklahoma State University (protocol code AS1655, 27 May 2016).

Informed Consent Statement: Informed consent was obtained from all subjects involved in the study.

Data Availability Statement: The data presented in this study are original to the authors and are openly available via the Oklahoma Oral History Research Program archives under the collection title "Building a Bigger Table" [https://library.okstate.edu/search-and-find/collections/digitalcollections/building-a-bigger-table (accessed on 11 March 2021)].

Acknowledgments: Many thanks to our project participants for sharing their stories. We are honored by their willingness to take time and energy to speak with us.

Conflicts of Interest: The authors declare no conflict of interest.

\section{References}

1. Dowler, E.A.; O'Connor, D. Rights-based approaches to addressing food poverty and food insecurity in Ireland and UK. Soc. Sci. Med. 2012, 74, 44-51. [CrossRef]

2. Robertson, A.; Tirado, C.; Lobstein, T.; Jermini, M.; Knai, C.; Jensen, J.H.; Ferro-Luzzi, A.; James, W.P.T. Food and Health in Europe: A New Basis for Action; WHO: Geneva, Switzerland, 2004.

3. Anderson, M.D.; Cook, J.T. Community food security: Practice in need of theory? Agric. Hum. Values 1999, 16, 141-150. [CrossRef]

4. Allen, P. Mining for justice in the food system: Perceptions, practices, and possibilities. Agric. Hum. Values 2008, 25, 157-161. [CrossRef]

5. Caruso, C.C. Searching for Food (Justice): Understanding Access in an Under-served Food Environment in New York City. J. Crit. Thought Prax. 2014, 3, 1-20. [CrossRef]

6. Berman, E. Promoting Food Security: The Community Food Security Coalition. J. Agric. Food Inf. 2011, 12, 221-231. [CrossRef]

7. Coleman-Jensen, A.; Gregory, C.; Singh, A. Household Food Security in the United States in 2013. SSRN Electron. J. 2014. [CrossRef]

8. Riches, G. Food Banks and Food Security: Welfare Reform, Human Rights and Social Policy. Lessons from Canada? Soc. Policy Adm. 2002, 36, 648-663. [CrossRef]

9. Riches, G. Thinking and acting outside the charitable food box: Hunger and the right to food in rich societies. Dev. Prac. 2011, 21, 768-775. [CrossRef]

10. Wekerle, G.R. Food Justice Movements: Policy, Planning, and Networks. J. Plan. Educ. Res. 2004, 23, 378-386. [CrossRef] 
11. Bedore, M. Food Desertification: Situating Choice and Class Relations within an Urban Political Economy of Declining Food Access. Stud. Soc. Justice 2014, 8, 207-228. [CrossRef]

12. Kato, Y. Not Just the Price of Food: Challenges of an Urban Agriculture Organization in Engaging Local Residents. Sociol. Inq. 2013, 83, 369-391. [CrossRef]

13. Pothukuchi, K.; Kaufman, J.L. Placing the food system on the urban agenda: The role of municipal institutions in food systems planning. Agric. Hum. Values 1999, 16, 213-224. [CrossRef]

14. Power, E.M. Combining Social Justice and Sustainability for Food Security. In Hunger Proof Cities: Sustainable Urban Food Systems; Koc, M., MacRae, R., Mougeot, L.J.A., Walsh, J., Eds.; International Research Development Center: Ottawa, ON, Canada, 1999; pp. 30-37.

15. Dowler, E.; Caraher, M. Local Food Projects: The New Philanthropy? Political Q. 2003, 74, 57-65. [CrossRef]

16. Long, M.A.; Gonçalves, L.; Stretesky, P.B.; DeFeyter, M.A. Food Insecurity in Advanced Capitalist Nations: A Review. Sustain. J. Rec. 2020, 12, 3654. [CrossRef]

17. Harvey, D. A Brief History of Neoliberalism; Oxford University Press: New York, NY, USA, 2005.

18. Gilmore, R.W. Golden Gulag: Prisons, Surplus, Crisis and Opposition in Globalizing California; University of California Press: Los Angeles, CA, USA, 2007.

19. Hartmann, C. Post neoliberal Public Health Care Reforms: Neoliberalism, Social Medicine, and Persistent Health Inequalities in Latin America. Am. J. Pub. Health 2016, 106, 2145-2151. [CrossRef] [PubMed]

20. Alkon, A.H. Food Justice and the Challenge to Neoliberalism. Gastronomica 2014, 14, 27-40. [CrossRef]

21. Regilme, S.S.F. The decline of American power and Donald Trump: Reflections on human rights, neoliberalism, and the world order. Geoforum 2019, 102, 157-166. [CrossRef]

22. Roy, A. Public Power in the Age of Empire. Socialist Worker. 3 September 2004. Available online: http://socialistworker.org/2004 -2/510/510_06_Roy.shtml (accessed on 9 January 2021).

23. Peck, J.; Tickell, A. Neoliberalizing Space. Antipode 2002, 34, 380-404. [CrossRef]

24. Hasenfeld, Y.; Garrow, E.E. Nonprofit Human-Service Organizations, Social Rights, and Advocacy in a Neoliberal Welfare State. Soc. Serv. Rev. 2012, 86, 295-322. [CrossRef]

25. Jones, S.J.; Craig, J.D.; Younginer, N.; Whitt, O.; Childers, C.; Draper, C.; Freedman, D.A.; Blake, C.E.; Liese, A.D. How Cultural Frames Guide Strategies to Eliminate Child Hunger. J. Poverty 2019, 24, 1-23. [CrossRef]

26. Smith-Carrier, T.; Ross, K.; Kirkham, J.; Pierce, B.D. 'Food is a Right ... Nobody Should Be Starving on Our Streets': Perceptions of Food Bank Usage in a Mid-Sized City in Ontario, Canada. J. Hum. Rts. Prac. 2017, 9, $29-49$.

27. U.N. Office of the High Commissioner of Human Rights (UNHCR). The Right to Adequate Food: Fact Sheet No. 34 . Available online: https://www.ohchr.org/Documents/Publications/FactSheet34en.pdf (accessed on 11 November 2020).

28. U.N. Office of the High Commissioner of Human Rights (UNHCR). CESCR General Comment No. 12: The Right to Adequate Food (Art. 11). 1999. Available online: https:/ / www.refworld.org/pdfid/4538838c11.pdf (accessed on 11 November 2020).

29. U.N. Universal Declaration of Human Rights. 1948. Available online: http://www.un.org/en/universal-declaration-humanrights / (accessed on 11 November 2020).

30. FAO. World Food Summit 1996. Rome Declaration on World Food Security. Available online: http://www.fao.org/wfs/index_ en.htm (accessed on 20 February 2012).

31. Mann, J. Dignity and Health: The UDHR's Revolutionary First Article. Health Hum. Rights 1998, 3, 30-38. [CrossRef] [PubMed]

32. Gewirth, A. Human Dignity as the Basis of Rights. In The Constitution of Rights: Human Dignity and American Values; Meyer, M.J., Parent, W.A., Eds.; Cornell University Press: Ithaca, NY, USA, 1992; pp. 10-28.

33. Nordenfelt, L. The Varieties of Dignity. Health Care Anal. 2004, 12, 69-81. [CrossRef] [PubMed]

34. Berger, P.; Luckman, T. The Social Construction of Reality; Anchor Books/Doubleday: New York, NY, USA, 1967.

35. Hodgkiss, P. A Moral Vision: Human Dignity in the Eyes of the Founders of Sociology. Sociol. Rev. 2013, 61, 417-439. [CrossRef]

36. Peffer, R.G. Marxism, Morality, and Social Justice; Princeton University Press: Princeton, NJ, USA, 2014.

37. Jacobson, N.; Oliver, V.; Koch, A. An urban geography of dignity. Health Place 2009, 15, 725-731. [CrossRef] [PubMed]

38. Miller, A.B.; Keys, C.B. Understanding Dignity in the Lives of Homeless Persons. Am. J. Community Psychol. 2001, 29, 331-354. [CrossRef]

39. Snow, D.A.; Anderson, L. Identity Work Among the Homeless: The Verbal Construction and Avowal of Personal Identities. Am. J. Sociol. 1987, 92, 1336-1371. [CrossRef]

40. Parr, H. Interpreting the 'hidden social geographies' of mental health: Ethnographies of inclusion and exclusion in semiinstitutional places. Health Place 2000, 6, 225-237. [CrossRef]

41. Seltser, B.J.; Miller, D.E. Homeless Families: The Struggle for Dignity; University of Illinois Press: Champaign, IL, USA, 1993.

42. Goffman, E. Stigma; Penguin: London, UK, 1963.

43. Goffman, E. Symbols of Class Status. Br. J. Sociol. 1951, 2, 294. [CrossRef]

44. Rogers-Dillon, R. The dynamics of welfare stigma. Qual. Sociol. 1995, 18, 439-456. [CrossRef]

45. Sykes, J.; Kriz, K.; Edin, K.; Halpern-Meekin, S. Dignity and Dreams: What the Earned Income Tax Credit (EITC) Means to Low-Income Families. Am. Soc. Rev. 2015, 80, 243-267. [CrossRef]

46. Horton, R. Rediscovering human dignity. Lancet 2004, 364, 1081-1085. [CrossRef] 
47. Gundersen, C.; Dewey, A.; Kato, M.; Crumbaugh, A.; Strayer, M. Map the Meal Gap 2019: A Report on County and Congressional District Food Insecurity and County Food Cost in the United States in 2017; Feeding America: Chicago, IL, USA, 2019.

48. Freudenberg, N.; Goldrick-Rab, S.; Poppendieck, J. College Students and SNAP: The New Face of Food Insecurity in the United States. Am. J. Public Health 2019, 109, 1652-1658. [CrossRef] [PubMed]

49. Soldavinia, J.; Bernerb, M.; Da Silvac, J. Rates of and Characteristics Associated with Food Insecurity Differ Among Undergraduate and Graduate Students at a Large Public University in the Southeast United States. Prev. Med. Reps. 2019, 14, 1-8. [CrossRef] [PubMed]

50. Schreier, M. Qualitative Content Analysis in Practice; Sage: Thousand Oaks, CA, USA, 2012.

51. Corbin, J.; Strauss, A. Basics of Qualitative Research: Techniques and Procedures for Developing Grounded Theory, 3rd ed.; Sage Publications, Inc.: Thousand Oaks, CA, USA, 2008; ISBN 9781412906432.

\section{Short Biography of Authors}

Amy Herrington is a Law Clerk at the U.S. Department of Justice. She received an MS in Sociology from Oklahoma State University in 2017 and a Juris Doctor from Vermont Law School in 2020. Her research and academic background focuses on environmental justice, community engagement, and international human rights law.

Tamara L. Mix is the Dresser Professor of Rural Sociology and Department Head at Oklahoma State University. She has research interests in environmental justice, social movements, and race, class and gender inequality. A qualitative researcher, she has conducted projects involving a diverse range of stakeholders focusing on environmental contamination in communities, water access and quality, food justice and security, and the human dimensions of resource extraction and production. 